\title{
A Four-Quadrant Thrust Estimation Scheme Based on Chebyshev Fit and Experiment of Ship Model
}

\author{
Baoyu Ye ${ }^{1}$, Qinruo Wang ${ }^{2}$, Jiafu Wan ${ }^{*}, 3$, Yi Peng ${ }^{2}$ and Jianbin Xiong ${ }^{2}$ \\ ${ }^{I}$ Aircraft Maintenance Engineering College, Guangzhou Civil Aviation College, China \\ ${ }^{2}$ Faculty of Automation, Guangdong University of Technology, Guangzhou, China \\ ${ }^{3}$ School of Computer Science and Engineering, South China University of Technology, Guangzhou, China
}

\begin{abstract}
This paper proposes a thrust estimation scheme for marine propellers in four-quadrant operations. To calculate the thrust and torque coefficients of screw propeller in four-quadrant, a Chebyshev fit expression of the propeller properties in four-quadrant for surface vessel is given, and then it is changed into an ordinary polynomial expression. These expressions are suitable for calculating the value of the propeller thrust and convenient for studying the ship's maneuverability. On the basis of ship-propeller movement characteristics, the dynamical models of propeller in fourquadrant operations are given. The effectiveness of the proposed thrust estimation scheme is validated by experimental results derived from an electrically driven fixed pitch propeller, which provides a good reference for the vessel operations.
\end{abstract}

Keywords: Propeller, Chebyshev polynomial, four-quadrant property, thrust estimation.

\section{INTRODUCTION}

In the design of vessel control system, such as Dynamic Positioning (DP), thruster assisted position mooring (PM), and autopilot, the high-level control approaches have received more attention compared to the propeller dynamics [1]. However, the issue of local thruster dynamics and control has been fully studied in the last ten years (see [2-9] and the references therein). There are two difficulties in the design of effective propeller controllers: 1) the propeller's dynamics modeling, and 2) measuring the environmental state. In extreme conditions, thrusters on ships are frequently subject to thrust losses that are caused by ventilation and in-and-out-of water effects. Moreover, due to the interaction between vessel hull and propeller, there are also losses of thrust. Industrial experience showed that the propulsion unit would be severe mechanical wear and tear due to the high thrust losses [10]. Therefore, the knowledge of the propeller thrust, either measured or estimated, could be used to improve the total performance of the vessel and reduce power fluctuations as well as wear and tear of the propulsion in extreme conditions [1].

All these considerations motivate the development of schemes to estimate the propeller thrust since in general it can't be measured directly. The incorporation of the estimated thrust in a controller is essential for the total performance of the vessel. In addition, the performance monitoring could improve fault detection and thrust allocation from calm to extreme sea conditions [11-15].

Zhinkin [16] proposed a thrust estimation scheme for the propeller, where the thrust values were computed on the condition of positive shaft speed and vessel speed in calm sea.

*Address correspondence to this author at School of Computer Science and Engineering, South China University of Technology, Guangzhou, China; Tel:+86 13143737141;Email:jiafu_wan@ieee.org
Its estimation was based on the measurement of the propeller torque and a linear relation between thrust and torque. The topic of thrust estimation has also been investigated in [17], the propeller thrust values were provided by the propeller torque obtained with a Kalman filter where a linear shaft friction torque was considered. The relation between thrust and torque involved an axial flow velocity model and a requirement of the knowledge of the advance speed, both of which are very difficult to measure. Furthermore, simulation results showed that the scheme was highly sensitive to hydrodynamic and mechanical modeling errors. Another example of thrust estimation scheme can be found in $[1,5,18]$. This scheme involved a nonlinear observer to estimate the propeller torque as well as shaft speed and computed the thrust from the observer estimates by a mapping.

In this paper, a thrust estimation scheme that works in fourquadrant plane is given. Unlike the method in $[1,5,18]$, our new scheme just need to know the propeller speed so as to compute the thrust by the relation between thrust and propeller speed, which makes it very convenient for studying the ship's maneuverability. In order to simulate the dynamic properties of the propeller load, this paper selects advance ratio of the bounded mode along with the test atlas of Nordstrom series and adopts the fitting method of Chebyshev polynomial. The thrust and torque coefficients can also be adjusted according to different numbers of propeller blades and area ratio. The thrust estimation scheme presented in this paper is based on the results achieved in these work.

This paper is organized as follows. Section 2 introduces the propeller model and the bounded form of advance ratio $J$. Section 3 presents the Chebyshev polynomial expression of propeller properties and its ordinary polynomial expression. Section 4 is devoted to verifying the effectiveness of our new thrust estimation scheme by experiment results. Finally, the conclusions were drawn in Section 5. 


\section{PROPELLER MODEL}

\section{Propeller Mathematical Model}

As shown in Fig. (1), the propeller system composed of an electric motor attached to the propeller through a shaft and a gear-box.

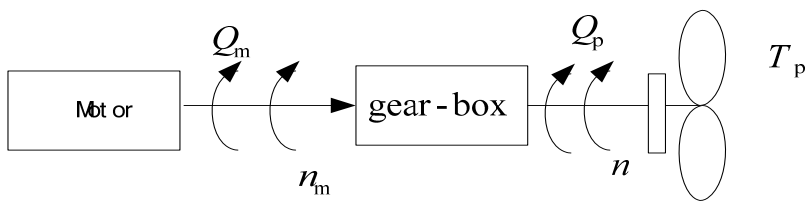

Fig. (1). Propeller system.

The function of motor is to provide power, then with the form of torque output, which is converted to thrust through the propellers rotating to push the ship forward. The propeller thrust and torque mathematical model can be written as [19]:

$$
\begin{aligned}
& F_{T}=\rho n^{2} D^{4} K_{T} \\
& M_{Q}=\rho n^{2} D^{5} K_{Q}
\end{aligned}
$$

where $F_{T}$ is the propeller thrust $(\mathrm{N}), M_{Q}$ is the propeller torque $(\mathrm{Nm}), n$ is the propeller $\operatorname{speed}(\mathrm{r} / \mathrm{s}), \rho$ is water density $\left(\mathrm{kg} / \mathrm{m}^{3}\right), D$ is propeller diameter $(\mathrm{m}), K_{T}$ is the thrust coefficient, and $K_{Q}$ is the torque coefficient.



Fig. (2). Measurement system.

In this paper, a supply ship model with two tunnel thrusters and two azimuth thrusters is presented. PLC analog output module output voltage $(0 \sim 6 \mathrm{v})$ corresponding to the propeller speed $n(0 \sim 3000 \mathrm{rpm})$ by controlling the motor servo drive. The azimuth thrusters' orientation is controlled by the synchronous measurement system, which is composed of the rotating transformer and the decoder board. A picture of the measurement system is presented in Fig. (2). This guarantee high reliability when it works in extreme sea states.

\section{Advance Ratio $J$ with Bounded Form}

If the propeller speed $n \neq 0$, the thrust coefficient $K_{T}$, torque coefficient $K_{Q}$ and advance ratio $J$ can be written as:

$K_{T}=F_{T} /\left(\rho n^{2} D^{4}\right)$
$K_{Q}=M_{Q} /\left(\rho n^{2} D^{5}\right)$

$J=\frac{v_{p}}{n \cdot D}$

where $J$ is the advance ratio, $v_{p}$ is advance speed of the propeller relative to water. Note that although in general $v_{p}$ is not available, it can be estimated by the following formula:

$v_{p}=v_{s}(1-w)$

where $v_{s}$ stands for vessel speed $(\mathrm{m} / \mathrm{s}) ; w$ stands for the wake fraction number.

For a given screw pitch ratio $H / D, K_{T} K_{Q}$ are plotted as functions of $J$ :

$K_{T}=K_{T}(J)$

$K_{Q}=K_{Q}(J)$

Generally speaking, the $K_{T}$ and $K_{Q}$ curves may stride across four quadrants. That is, when $n \rightarrow 0, J, K_{T}, K_{Q} \rightarrow \infty$. This expression is usually called the non-bounded form. Theoretically, the curves can be established even though $J>1$, but it's troublesome for both analog simulation and digital simulation when the variable range is very large. It will be more convenient to use the following form to analysis the propeller's dynamic property in four-quadrant. When $n$ and $v_{p}$ are not equal to zero simultaneously, they are defined as

$K_{T}{ }^{\prime}=F_{T} /\left[\rho D^{2}\left(v_{p}^{2}+D^{2} n^{2}\right)\right]$

$K_{Q}{ }^{\prime}=M_{Q} /\left[\rho D^{3}\left(v_{p}^{2}+D^{2} n^{2}\right)\right]$

$J^{\prime}=v_{p} /\left[(D|n|) \sqrt{1+\left(v_{p} / D n\right)^{2}}\right]$

The following transformation relation holds:

$$
J^{\prime}=\left\{\begin{array}{lc}
1 & n=0, v_{p}>0 \\
J / \sqrt{1+J^{2}} & n>0 \\
-J / \sqrt{1+J^{2}} & n<0 \\
-1 & n=0, v_{p}<0
\end{array}\right.
$$

It can be seen that by $(12), J \in(-\infty,+\infty)$ is mapped into $J^{\prime} \in[-1,1]$. That is, the propeller's all-round dynamic is expressed by the bounded mode. The relationships between $K_{T}$ and $J^{\prime}, K_{Q}$ and $J^{\prime}$ become:

$$
\begin{aligned}
& K_{T}{ }^{\prime}=\left(K_{T} n^{2} D^{2}\right) /\left(v_{p}^{2}+n^{2} D^{2}\right)=K_{T}\left(1-J^{\prime 2}\right) \\
& K_{Q}{ }^{\prime}=\left(K_{Q} n^{2} D^{2}\right) /\left(v_{p}^{2}+n^{2} D^{2}\right)=K_{Q}\left(1-J^{\prime 2}\right)
\end{aligned}
$$

\section{CHEBYSHEV POLYNOMIAL EXPRESSION OF PROPELLER PROPERTIES}

A continuous function over the interval of [-1 1] can be expressed approximately as an $\mu$-th order Chebyshev polynomial: 
$f(x)=\frac{1}{2} a_{0} g_{0}(x)+a_{1} g_{1}(x)+\cdots+a_{\mu T} g_{\mu}(x)$

where $g_{0}(x)=1, g_{1}(x)=x, g_{2}(x)=2 x^{2}-1, \cdots$. The general recursive formula for $g_{k}(x)$ is:

$g_{k}(x)-2 x g_{k-1}(x)+g_{k-2}(x)=0(k \geq 2)$

Note that $g_{j}$ and $g_{k}$ are orthogonal to each other, and the polynomial coefficients are independent of the order $\mu$. Besides, the fitting error is small and the fitting result with finite order $\mu$ is the best approximation in the sense of minimal square error. It's also convenient to change a given Chebyshev polynomial expression into an ordinary polynomial. The Chebyshev polynomial coefficients $a_{0} \sim a_{\mu}$ are substituted into (15) and $g_{0} \sim g_{\mu}$ are extended by definition, and then the ordinary polynomial and its coefficients $b_{0} \sim b_{\mu}$ can be obtained. $K_{T}^{\prime}$ and $K_{Q}^{\prime}$ show as functions of the bounded advance ratio $J$ ', which can be written as

$K_{T}^{\prime}\left(J^{\prime}\right)=\frac{1}{2} a_{0 T} g_{0}\left(J^{\prime}\right)+a_{1 T} g_{1}\left(J^{\prime}\right)+\cdots+a_{\mu T} g_{\mu}\left(J^{\prime}\right)$

$K_{Q}{ }^{\prime}\left(J^{\prime}\right)=\frac{1}{2} a_{0 Q} g_{0}\left(J^{\prime}\right)+a_{1 Q} g_{1}\left(J^{\prime}\right)+\cdots+a_{\mu Q} g_{\mu}\left(J^{\prime}\right)$

where coefficients $a_{0} \sim a_{\mu}$ can be obtained from Tables 1 and 2 in [20]. Extending $g_{0} \sim g_{\mu}$ in (17) and (18) by definition, the ordinary polynomials corresponding to (17) and (18) can be written as:

$K_{T}{ }^{\prime}\left(J^{\prime}\right)=b_{0 T}+b_{1 T} J^{\prime}+\cdots+b_{\mu T}\left(J^{\prime}\right)^{\mu}$

$K_{Q}{ }^{\prime}\left(J^{\prime}\right)=b_{0 Q}+b_{1 Q} J^{\prime}+\cdots+b_{\mu Q}\left(J^{\prime}\right)^{\mu}$

Trading off the accuracy and efficiency in terms of actual simulation of the ship, the 8-th order Chebyshev polynomial is adopted in this study. Therefore, $a_{0} \sim a_{8}$ can be obtained from Tables 1 and $\mathbf{2}$ in the appendix of [20]. With the pitch ratio $H / D=1.0$, the coefficient are listed in Table 1 for ease of reference.

The test atlas of Nordstorm series in [21] can estimate the propeller characteristics curve in four-quadrant. The principal parameters of this series of propellers are: 1) disc square ratio $A / A_{d}=0.45,2$ ) number of blades $Z=4$, and 3 ) screw pitch ratio $H / D=0 \sim 1$.6. In case the actual parameters are different from the test atlas of Nordstorm series, that is,
$A / A_{d} \neq 0.45$, and/or $Z \neq 4$, the following formulas can be used [21]:

$K_{T}{ }^{\prime \prime}=\alpha K_{T}^{\prime}$

$K_{Q}{ }^{\prime \prime}=\alpha K_{Q}{ }^{\prime}$

where $K_{T}{ }^{\prime \prime}, K_{Q}$ " are the modified coefficients, The conversion factor $\alpha=\sqrt[3]{Z_{0}\left(A / A_{d}\right)_{0} /\left[Z\left(A / A_{d}\right)\right]}$, where $Z_{0}=4,\left(A / A_{d}\right)_{0}=0.45, Z$ is the actual number of blades, $A / A_{d}$ is the actual disc square ratio. The characteristics of $K_{T}{ }^{\prime \prime}=\alpha K_{T}{ }^{\prime}\left(J^{\prime}\right)$ and $K_{Q}{ }^{\prime \prime}=\alpha K_{Q}{ }^{\prime}\left(J^{\prime}\right)$ are shown in Fig. (3a, b). For the convenience of simulation, the Chebyshev polynomial is often changed into an ordinary polynomial, namely, (17) and (18) are changed into (19) and (20). Respectively, the results are shown in Table 2 with respect to the method mentioned above

\section{EXPERIMENTAL RESULTS}

\section{A. Ship-Propeller model}

According to theorem of momentum and Newton's second law, the motion equation of the ship-propeller system is established as follows

$2 \pi I \dot{n}=R_{a b} Q_{m}-Q_{p}-Q_{f}$

$(m+\Delta m) \frac{d v_{s}}{d t}=F_{T E}-R$

where $I$ is the total moment of inertia including additional moment of inertia, $Q_{m}$ is the motor torque, $Q_{P}$ is the propeller torque, $R_{a b}$ is the gear ratio, $Q_{f}$ is the static friction torque, $m$ is the quality of the ship $(\mathrm{kg}), \Delta m$ is additional quality of the ship $(\mathrm{kg})$, and $R$ is total resisting force, which can be written as [22]:

$R=r v_{s}^{2}$

with $r$ being the total resistance coefficient of the ship and constant at given condition.

Here, the gear ratio and the static friction torque are chosen as

$R_{a b}=3, Q_{f}=(0.02 \sim 0.04) Q_{m}$

According to the analyses in previous sections, a combination of (1) (2) (9) (10) (21) and (22) yields:

$$
F_{T}=K_{T} \rho D^{2}\left(v_{p}^{2}+n^{2} D^{2}\right)=\alpha K_{T}{ }^{\prime} \rho D^{2} v_{p}^{2} / J^{\prime 2}
$$

Table 1. Chebyshev Polynomial Coefficients of Thrust and Torque Properties

\begin{tabular}{|c|c|c|c|c|c|c|c|c|c|c|}
\hline \multicolumn{2}{|c|}{} & $a_{0}$ & $a_{2}$ & $a_{2}$ & $a_{3}$ & $a_{4}$ & $a_{5}$ & $a_{6}$ & $a_{7}$ & $a_{8}$ \\
\hline \hline \multirow{2}{*}{$K_{T}{ }^{\prime}$} & $n>0$ & 0.3888 & -0.2338 & -0.1664 & -0.02003 & 0.001340 & 0.05341 & -0.02842 & 0.02029 & 0.01766 \\
\cline { 2 - 39 } & $n<0$ & -0.2641 & -0.2274 & 0.1254 & -0.02646 & -0.001524 & 0.04883 & 0.02704 & 0.01888 & -0.006320 \\
\hline \multirow{2}{*}{$K_{Q}{ }^{\prime}$} & $n>0$ & 0.05315 & -0.03093 & -0.02260 & -0.004060 & 0.0008315 & 0.006672 & -0.001843 & 0.004078 & 0.002371 \\
\cline { 2 - 13 } & $n<0$ & -0.04467 & -0.03423 & 0.02490 & -0.004576 & -0.001535 & 0.007792 & 0.004162 & 0.004694 & -0.001648 \\
\hline
\end{tabular}






a) Thrust characteristics

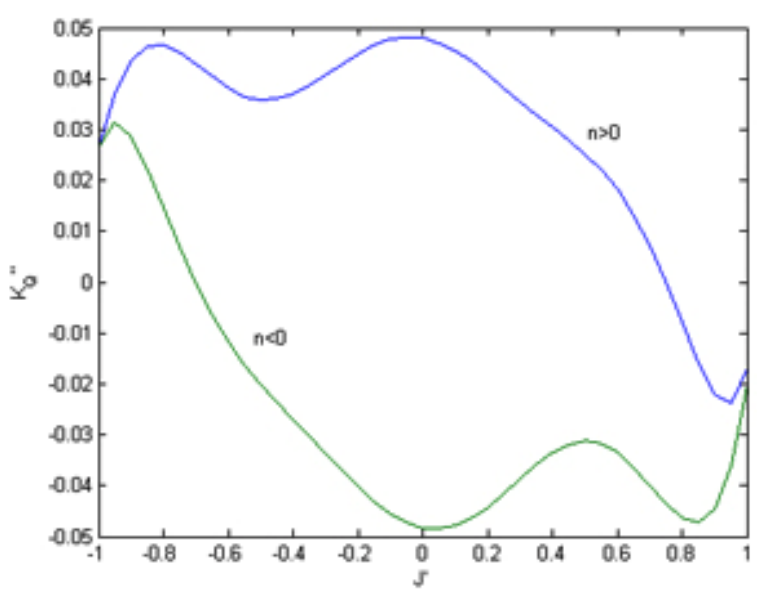

b ) Torque characteristics

Fig. (3). Four-quadrant propeller characteristics.

Table 2. Ordinary Polynomial Coefficients of Thrust and Torque Properties

\begin{tabular}{|c|c|c|c|c|c|c|c|c|c|c|}
\hline \multicolumn{2}{|c|}{$b$} & $b_{0}$ & $b_{1}$ & $b_{2}$ & $b_{3}$ & $b_{4}$ & $b_{5}$ & $b_{6}$ & $b_{7}$ & $b_{8}$ \\
\hline \hline \multirow{2}{*}{$K_{T}{ }^{\prime}$} & $\mathrm{n}>0$ & 0.4082 & -0.0487 & -1.4202 & -0.0121 & 4.2005 & -1.4179 & -5.4304 & 1.2986 & 2.2605 \\
\cline { 2 - 38 } & $\mathrm{n}<0$ & -0.2923 & -0.0360 & 0.9520 & -0.0252 & -2.3213 & -1.3333 & 2.4832 & 1.2083 & -0.8090 \\
\hline \multirow{2}{*}{$K_{Q}{ }^{\prime}$} & $\mathrm{n}>0$ & 0.0542 & -0.0139 & -0.1609 & 0.0787 & 0.4745 & -0.3500 & -0.6660 & 0.2610 & 0.3035 \\
\cline { 2 - 13 } & $\mathrm{n}<0$ & -0.0546 & -0.0144 & 0.1897 & 0.0887 & -0.4757 & -0.4011 & 0.5551 & 0.3004 \\
\hline
\end{tabular}

$M_{Q}=K_{Q} \rho D^{3}\left(v_{p}^{2}+n^{2} D^{2}\right)=\alpha K_{Q}{ }^{\prime} \rho D^{3} v_{p}^{2} / J^{12}$

For thrust deduction coefficient $\mathrm{t}$ :

$t=\left(F_{T}-F_{T E}\right) / F_{T}$, the propeller effective thrust $F_{T E}(\mathrm{~N})$ is given by

$F_{T E}=(1-t) F_{T}=(1-t) \alpha K_{T}{ }^{\prime} \rho D^{2} v_{p}^{2} / J^{\prime 2}$

In the ship simulation, due to lack of the measured data, especially the data of backward navigation, $t$ and $w$ are determined as [22]:

$$
\begin{aligned}
& \begin{cases}t=0.33 & n<n_{e} \\
t=-0.33 n / n_{e} & -n_{e} \leq n<0 \\
t=0.13 n / n_{e} & 0 \leq n<n_{e} \\
t=0.13 & n \geq n_{e}\end{cases} \\
& \begin{cases}w=0 & v_{s} \leq 0 \\
w=0.22 v_{s} / v_{s e} & 0 \leq v_{s}<v_{s e} \\
w=0.22 & v_{s} \geq v_{s e}\end{cases}
\end{aligned}
$$

where $v_{s e}$ stands for ship rated speed. Fig. (4) summarizes the motion equation of the ship-propeller system.

\section{B. Result Analysis}

The main purpose of this paper is to estimate the thrust from the relation between the thrust and the propeller speed. A ship-propeller model is given for the test of electric propulsion system with propellers. The test were performed at the ocean engineering Dynamic Positioning System lab in Guangdong university, where has a pool with length $\mathrm{L}=11 \mathrm{~m}$, wide $\mathrm{H}=6 \mathrm{~m}$. A $2.8 \mathrm{~m}$ ship model of an offshore supply vessel with a scale of 1:26 has been conducted (See Fig. 5). Fig. (6) shows design of the thrust estimate experiment scheme. The main parameters are shown in Table 3. At the condition of the given initial ship speed $v_{s}, J$ ' is computed from (6) and (11), $K_{T}{ }^{\prime}, K_{Q}{ }^{\prime}$ can be obtained by (17) and (18). Then the propeller torque and effective thrust can be calculated by (27) and (28). Ship speed can be obtained by (24) (27) and (29).

The rated vessel speed of $2.8 \mathrm{~m}$ ship model is $v_{s e}=1 \mathrm{~m} / \mathrm{s}$ by test. This measuring experiment record a propeller thrust of the corresponding propeller speed every 20 RPM from- 1000 $\sim 1000$ RPM. Fig. (7) gives the experiment and theoretical values of propeller thrust.

Using the model given in (27) and (28), combined with the $K_{T}{ }^{\prime}, K_{Q}{ }^{\prime}$ values obtained by (17) and (18), the propeller thrust can be estimated under the given propeller speed. Fig. (7) shows the measured and estimated thrust from the static water. It can be seen from Fig. (7) that the propeller thrust increases with the increase of the propeller speed $n$; and for the same propeller speed $n$, the thrust in the case of the propeller reverse is less than that when the propeller is in positive rotation. That is, for positive values of $n$, the efficiency is higher because the propeller was designed to work mainly at forward vessel speed. 


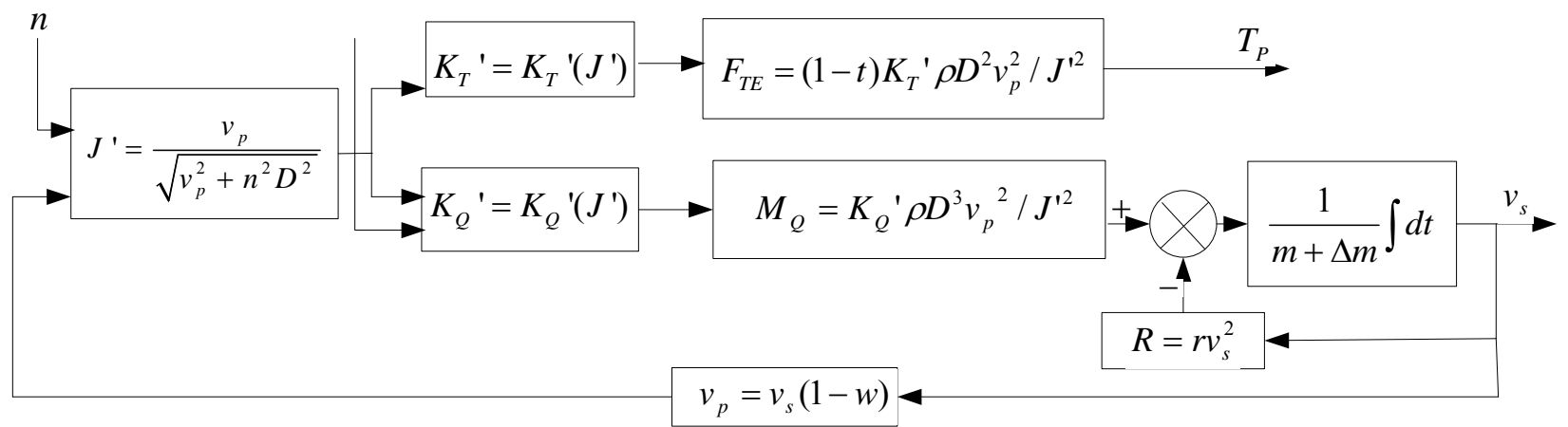

Fig. (4). Ship-propeller system.

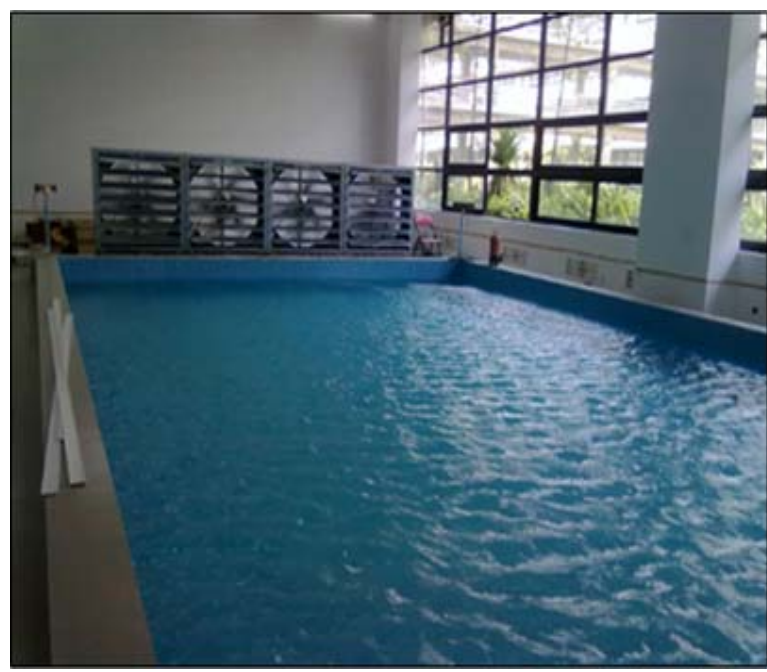

a ) pool

Fig. (5). Ship model: scale 1:26 of a supply vessel.

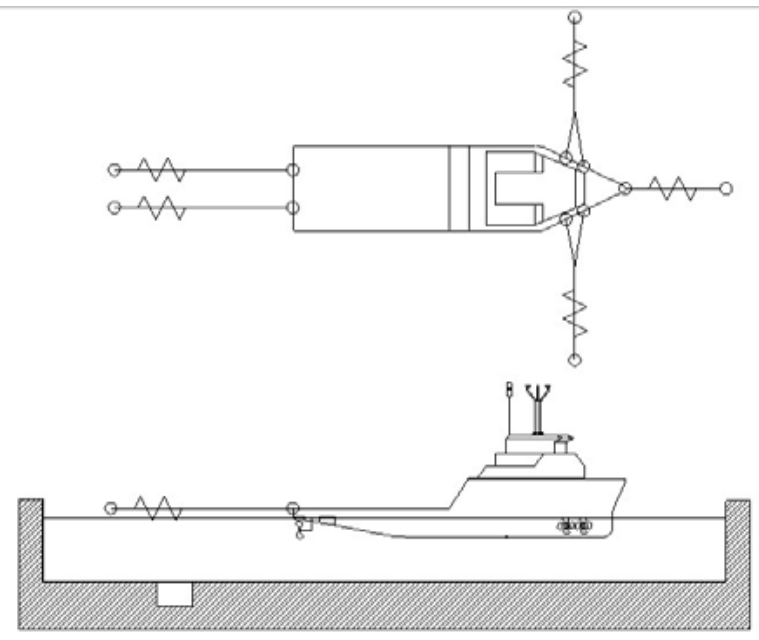

a) Experimental schemes

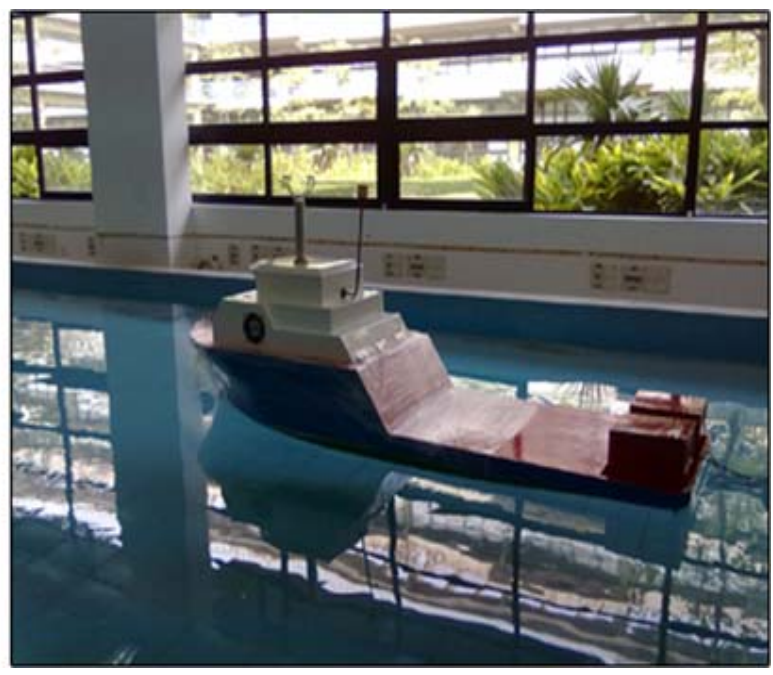

b ) Ship model



b) Experimental physical map

Fig. (6). Thrust estimate experiment scheme design. 
Table 3. Parameters of Vessel

\begin{tabular}{|c|c|c|c|c|c|c|c|}
\hline $\begin{array}{c}\text { Length } \\
\text { Overall (m) }\end{array}$ & $\begin{array}{c}\text { Overall } \\
\text { Width (m) }\end{array}$ & $\begin{array}{c}\text { Mean Draught } \\
(\mathbf{m})\end{array}$ & $\begin{array}{c}\text { H/D (Pitch } \\
\text { Ratio) }\end{array}$ & $\begin{array}{c}\text { M (Quality) } \\
(\mathbf{k g})\end{array}$ & $\begin{array}{c}\text { D (Propeller } \\
\text { Diameter) (m) }\end{array}$ & $\begin{array}{c}A / A_{d}(\text { Disc } \\
\text { Square Ratio) }\end{array}$ & $\begin{array}{c}\rho(\text { Water Density) } \\
\left(\mathbf{k g} / \mathbf{m}^{3}\right)\end{array}$ \\
\hline \hline 2.8 & 0.762 & 0.167 & 1 & 230 & 0.15 & 0.65 & 1025 \\
\hline
\end{tabular}

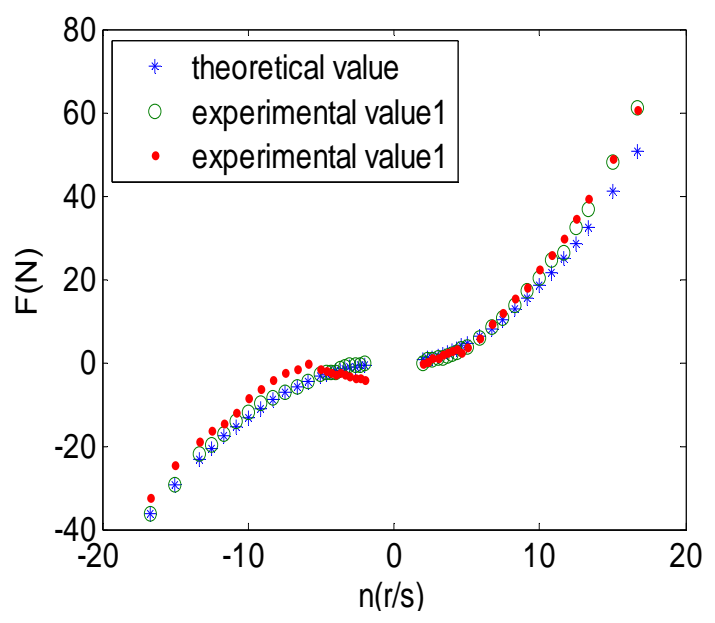

Fig. (7). Thrust experiment and theoretical values.

\section{CONCLUSIONS}

In this paper, a thrust estimation scheme for marine propellers across the full four-quadrant range is presented. First, the propeller properties across four quadrants described with Chebyshev polynomial and its ordinary polynomial are given. Based on such polynomial, the simulation model of propeller in four-quadrant operations is established. The experiment results show that the performance of the thrust estimation scheme using the algorithm mentioned above is satisfactory. The proposed thrust estimation scheme will be used in high performance propeller controllers and thrust allocation for ship control.

\section{ABOUT THE AUTHORS}

Baoyu Ye is now an instructor at Guangzhou Civil Aviation College, Guangzhou, China. Her current research interests include ship motion control, automation equipment and control technology.

Qinruo Wang is now with School of Automation Science and Engineering, Guangdong University of Technology, China as Prof. and instructor of Ph.D. His current research interests include integrative technology of machine and electricity and automatic network control.

Jiafu Wan is currently an associate research fellow in School of Computer Science and Engineering of South China University of Technology. His current research interests are cyber-physical systems, embedded systems, internet of things, and machine- to-machine communications.

Yi Peng is now a teaching assistant at Guangdong University of Technology, Guangzhou, China, His current research is automation equipment and control technology.

Jianbing Xiong is now a Ph.D. candidate at Guangdong University of Technology, Guangzhou, China. His current research interests include data mining, information security, and computer application technology.

\section{CONFLICT OF INTEREST}

The authors confirm that this article content has no conflict of interest.

\section{ACKNOWLEDGEMENTS}

This work is supported by the National Natural Science Foundation of China No. 50905063; the Natural Science Foundation of Guangdong Provincial of China under Grant No. 9151009001000021; the Key Item in the Guangdong Province Science \& Technology Special Program under Grant No. 2009A080202006; the Ministry of Education of Guangdong Province Special Fund funded projects through Cooperative under Grant No. 2009B090300341.

\section{REFERENCES}

[1] L. Pivano, T.A. Johansen, and Ø.N. Smogeli, "A Four-quadrant thrust estimation scheme for marine propellers: theory and experiments", IEEE Transactions on Control Systems Technology, vol. 17, no. 1, pp. 215-225, 2009.

[2] L.L. Whitcomb, and D. Yoerger, "Development comparison and preliminary experimental validation of nonlinear dynamic thruster models", IEEE Journal of Oceanic Engineering, vol. 24, no. 4, pp. 481-494, 1999.

[3] R. Bachmayer, L.L.Whitcomb, and M.A. Grosenbaugh, "An accurate four-quadrant nonlinear dynamical model for marine thrusters: Theory and experimental validation", IEEE Journal of Oceanic Engineering., vol. 25, no. 1, pp. 146-159, 2000.

[4] M. Blanke, K. Lindegaard, and T.I. Fossen, "Dynamic model for thrust generation of marine propellers", In: Proc. 5th IFAC Conf. Manoeuvring Control Marine Craft (MCMC), Aalborg, Denmark, pp. 363-368, 2000.

[5] L. Pivano, T.I. Fossen, and T.A. Johansen, "Experimental validation of a marine propeller thrust estimation scheme", Is presented at the 7th IFAC conf. Manoeuvring control marine craft (MCMC), Lisbon, Portugal, 2006.

[6] L. Pivano, T.I. Fossen, and T.A. Johansen, "Nonlinear model identification of a marine propeller over four-quadrant operations", In the 14th IFAC Symp. Syst. Identification (SYSID), Newcastle, Australia, 2006.

[7] L. Pivano, N. Smogeli, T.A. Johansen, T.I. Fossen, "Marine propeller thrust estimation in four-quadrant operations", In the 45th IEEE Conf. Dec. Control, San Diego, CA, 2006.

[8] R. Bachmayer, L.L. Whitcomb, and A. Grosenbaugh, "An accurate four-quadrant nonlinear dynamical model for marine thrusters: theory and experimental validation", IEEE Journal of Oceanic Engineering, vol. 25, no. 1, pp. 146-159, 2000.

[9] K. Koushan, "Environmental and interaction effects on propulsion systems used in dynamic positioning, an overview", In proceedings of the ninth international symposium on practical design of ships and other floating structures (PRADS'04), Lubeck-Tracemunde, Germany, 2004.

[10] Ø.N. Smogeli, A.J. Sørensen, and K.J. Minsaas, "The concept of anti-spin thruster control", Control Engineering Practice, vol. 16, no. 2008, pp. 465-481, 2006.

[11] M. Blanke, R. Izadi-Zamanabadi, and T.F. Lootsma, "Fault monitoring and reconfigurable control for ships propulsion plant", International Journal of Adaptative Control and Signal Processing, pp. 671-688, December 1998.

[12] Ø.N. Smogeli, "Control of marine propellers: from normal to extreme conditions, in Marine Technol", Norwegian Univ. Sci. 
Technol.(NTNU): Trondheim, Norway, 2006.

[13] Ø.N. Smogeli, A.J. Sørensen, and T.I. Fossen, "Design of a hybrid power/torque thruster controller with loss estimation", Is Presented at the IFAC Conf. Control Appl.Marine Syst. (CAMS), Ancona, Italy, 2004.

[14] L. Pivano, T. A. Johansen, Ø. N. Smogeli, and T. I. Fossen, "Nonlinear thrust controller for marine propellers in four-quadrant operations", In the 26th Amer. Conf.(ACC), New York, July 2007.

[15] T.F. Lootsma, "Observer-based fault detection and isolation for non-linear systems", In Control Eng., Aalborg Univ.: Aalborg, Eenmark, 2001.

[16] V.B. Zhinkin, "Determination of the screw propeller thrust when the torque or shaft power is known", In the 4th International Symposium on Practical Design of Ships and Mobile Units, Bulgaria, pp. 23-28, 1989.

[17] C. Guibert, E. Foulon, N. Ait-Ahmed, L. Loron, "Thrust control of electric marine thrusters", In the 31st Annu. Conf. IEEE Ind. Electron. Soc.(IECON), Raleigh, NC, 2005.

[18] L. Pivano , T.A. Johansen , Ø.N. Smogeli , and T.I. Fossen, "Nonlinear thrust controller for marine propellers in four-quadrant operations", In American Control Conference, New York, pp. 900905, 2007.

[19] J.S. Carlton, "Marine propellers and propulsion", ButterworthHeinemann Ltd: Oxford, UK, 1994.

[20] L. Dian-pu, W. Zone-yi, and C. Hai-hong, "Chebyshev fitting way and error analysis for propeller atlas four quadrants", Journal of Marine Science and Application, vol. 1, no. 1, pp. 52-59, 2002.

[21] J. Yuh, "Underwater robotic vehicles: design and control", Albuquerque TSI Press: USA, 1996.

[22] F. Shangyong, "Vehicle power setting and simulation technique", Shanghai: Shanghai Jiao Tong University, 1993.

Received: June 11, 2012

Revised: July 18, 2012

Accepted: July 19, 2012

(C) Ye et al.; Licensee Bentham Open.

This is an open access article licensed under the terms of the Creative Commons Attribution Non-Commercial License (http://creativecommons.org/licenses/by-nc/3.0/) which permits unrestricted, non-commercial use, distribution and reproduction in any medium, provided the work is properly cited. 